\title{
Response to Letter to the Editor on: Efficacy of Bracing versus Observation in the Treatment of Idiopathic Scoliosis (Evid Based Spine Care J 2011;2(2):25-34)
}

Evan M. Davies ${ }^{1}$ ${ }^{1}$ Southampton Children's Hospital, University Hospital Southampton,
Southampton, United Kingdom

Evid Based Spine Care J 2013;4:166.

We appreciate the comments from D. Schlenzka and T. Yrjonen. We thank you for your interest in our article.

We agree that the article by Mannherz et al does cover a younger age group of patients, but given the difficulty finding prospective follow-up in bracing treatments, it was included as it showed failure in long-term follow-up. ${ }^{1}$

The illustrative case demonstrates a patient with high compliance in that she was highly motivated to be braced, and continued to wish to be braced, despite earlier advice to the contrary that the brace treatment was failing to maintain the curve. The patient was premenarche at the time of treatment commencement. Continuation of treatment was purely at patient request.

In our institution, we have adopted the shared decisionmaking model for patient consent to treatment. ${ }^{2}$ All forms of treatment options are discussed with patients. Complications of observation, bracing, and surgical treatment are discussed. The clinician role is to allow patients to make the best individual decisions for their particular circumstances and this does vary between individuals and caregivers. Bracing is offered to patients at our institution, but the scientific evidence to support its use is compounded by the lack of large-scale multicenter and international trials to show that the brace will prevent curve deterioration and/or surgical intervention. We know that there is significant variation in cultural and regional patterns to brace compliance. Greg Houghton, in an article that would be difficult to
Address for correspondence Evan M. Davies, FRCS (Ed), Consultant Paediatric Spine Surgeon, Southampton Children's Hospital, University Hospital Southampton, Tremona Road, Southampton SO16 6YD, United Kingdom (e-mail: evan.davies@nhs.net).

replicate, placed electrodes within the brace that showed poor compliance. ${ }^{3}$ Patients often are psychologically affected by brace wearing in that it may turn a disease that is invisible to most visible to the majority. No treatment is without complication, and we need high-quality evidence to support and advocate and mentor patients in the use of any technology and treatment. Current, scientific literature is not as helpful as we would wish it to be in helping patients and caregivers make the best selection of care and decision making for their individual cases. The EBSJ offers a unique opportunity for the development of an appropriate, helpful, and scientifically validated randomized controlled trial in the use of bracing in idiopathic adolescent scoliosis (IAS). I would welcome such a development and an opportunity to help make better, more informed decision making in brace treatment in IAS.

\section{References}

1 Mannherz RE, Betz RR, Clancy M, Steel HH. Juvenile idiopathic scoliosis followed to skeletal maturity. Spine (Phila Pa 1976) 1988; 13(10):1087-1090

2 Moynihan R. The future of medicine lies in truly shared decision making. BMJ 2013;346:f2789

3 Chase AP, Bader DL, Houghton GR. The biomechanical effectiveness of the Boston brace in the management of adolescent idiopathic scoliosis. Spine (Phila Pa 1976) 1989;14(6):636-642 (c) 2013 Georg Thieme Verlag KG Stuttgart · New York
DOI http://dx.doi.org/ 10.1055/s-0033-1357354. ISSN 1663-7976. 